\title{
EL COSTO DE LOS DERECHOS SOCIALES
}

\author{
LUIS JAIME SALGAR VEGALARA
}

In order to protect rights, a state needs to spend some of its resources, and this is the subject of this article. It begins by studying the relationship between a state and the cost of protecting rights in light of the evolution of the modern state. The costs became clear with the contemporary and active form of the state known as the «Estado social de derecho», or Social State. The article uses the cost of protecting rights to dissolve a traditional distinction between «negative rights» and «positive rights», given that «negative rights» also need significant protection from the State. Finally, the article studies some cases associated with the cost of rights, and derives specific conclusions.

El propósito de estas páginas consiste en estudiar el tema relativo a las perspectivas del análisis del costo de los derechos a partir de tres líneas argumentativas diferentes. En primer lugar, busco explicar las razones que tengo para afirmar que la pregunta por el costo de los derechos sólo tiene sentido bajo el modelo del Estado social de derecho. Este punto se aborda con base en una comparación de la concepción acerca de los derechos en tres momentos de la historia, determinantes en el proceso de construcción del Estado según lo entendemos en la actualidad: el origen del Estado moderno mismo en plena Edad Media, el del Estado liberal burgués y el del Estado social de derecho. En segundo término, quiero demostrar que la diferencia entre derechos negativos y derechos positivos es presupuestalmente insostenible en el escenario económico actual; aclaro que utilizo los términos «derechos negativos» $\mathrm{y}$ «derechos positivos» con el mismo significado que se da en Francia a la contraposición entre «derechos restricción» y «derechos crédito», o «prestaciones» $\mathrm{y}$ «derechos negativos» en parte de la literatura estadounidense ${ }^{1}$.

\footnotetext{
${ }^{1}$ Cfr. Fioravanti, M., Los derechos fundamentales, Editorial Trotta, Madrid, 1998. p. 55.

Desafortunadamente la terminología no es uniforme. Maurizio Fioravanti, por ejemplo, distingue entre la esfera de las libertades civiles, las - negativas - y la esfera de las libertades políticas, las positivas -. Para efectos del presente escrito, se entiende que los «derechos negativos» son los civiles (básicamente propiedad y libertad) mientras que los «positivos» son los que implican una prestación individual y concreta por parte del Estado o en virtud a sus disposiciones. Los derechos políticos reciben aquí este mismo nombre: derechos políticos.
} 
Por último, se pone de manifiesto el alcance del tema sobre el costo de los derechos en el ámbito cotidiano de la actividad económica pública -y, en ocasiones, de la privada- a partir de algunos ejemplos.

\section{Notas aproximativas a tres momentos de la historia}

Voy a empezar esta sección con la siguiente afirmación: la pregunta por el costo de los derechos sólo tiene sentido en un sistema cuya función esencial sea la protección de los mismos. Parecería que se trata de una afirmación frágil o, en el mejor de los casos, tautológica. No obstante, un análisis histórico permite evidenciar que no se trata de una aseveración tan vacía como podría pensarse en un primer momento. El punto es el siguiente: el Estado moderno no nació como una institución encargada de garantizar o asegurar derechos sino que su condición de garante la adquirió luego de un proceso de varios siglos.

\section{El origen del Estado y la génesis de los «derechos negativos»}

El origen del Estado, que suele ubicarse en plena Edad Media, obedece a la unificación del poder en cabeza de una sola persona sobre un territorio determinado. Durante la segunda mitad de la Edad Media se registró una doble tendencia característica de las sociedades feudales occidentales: por un lado, la concentración de las armas por parte de los más poderosos -y la consecuente prohibición a los más débiles de que las usaran-y, por el otro, aunque simultáneamente, el uso de las acciones y litigios judiciales como mecanismo de circulación de la propiedad. Se trató de un uso de las acciones y de los litigios que no había tenido lugar antes en la historia. Más que «dar a cada uno lo suyo», las acciones y los litigios en los nacientes estados fueron utilizadas para garantizar que el señor se reservase el uso de la fuerza y que quienes actuaren en contravía de esta regla fueran sancionados. «Se comprende así por qué los más poderosos procuraron controlar los litigios judiciales, impidiendo que se desenvolviesen espontáneamente entre los individuos, y por qué intentaron apoderarse de la circulación judicial y litigiosa de los bienes, hecho que implicó la concentración de las armas y el poder judicial, que se formaba en esta época, en manos de los mismos individuos» ${ }^{2}$. Así, la finalidad principal de la «administración de justicia» en los estados medievales no fue la de garantizar el ejercicio de los derechos de las individuos sino la de asegurar que el soberano se reservara para sí el uso de la fuerza.

${ }^{2}$ Foucault, Michel. La verdad y las formas jurídicas, Editorial Gedisa, Barcelona, 1992. p. 74. 
Es cierto que esta función implicaba la asignación de derechos y obligaciones entre los miembros del feudo, pero ello era tan solo una consecuencia: la protección de los derechos y la consecuente conservación de la paz no eran valores en sí mismos sino beneficios derivados de la necesidad que tenía el soberano de preservar la inviolabilidad de su soberanía?

En este contexto, la Carta Magna de 1215 presenta una importancia enorme: la Carta Magna es un contrato suscrito por el Rey Juan y por los estamentos políticos con el propósito de delimitar el ámbito de ejercicio de poder del soberano y de reconocer los derechos en cabeza de los diferentes sectores y gremios de la comunidad. En términos generales, se considera que la importancia de la Carta Magna consiste en haber exigido que la imposición de nuevos impuestos estuviese sujeta a aprobación por parte del naciente Parlamento, el commune consilium regni, con el fin de limitar así las facultades del rey respecto de la propiedad privada; es decir, en haber creado la famosa fórmula según la cual no habrá impuestos sin representación (no taxation without representation, de acuerdo con su formulación inglesa).

No obstante, hay quienes van más allá. Sostienen que esta limitación de la prerrogativa del rey de imponer gravámenes sería expresión de otra cosa, en sí más relevante. «En efecto, ahora se manifiesta con claridad que con el mecanismo del consilium regni se está determinando una situación en la que los magnates del reino, todos juntos y junto al mismo rey, tienden a representar la comunidad política en su totalidad, con el conjunto de derechos y relaciones existentes en ella. [...] todas estas mismas fuerzas unidas, a través de la misma Carta, no hacen otra cosa que confirmar la existencia de un orden común, de una lex terrae, de una verdadera y cierta ley del país» ${ }^{4}$.

${ }^{3}$ La posición expresada en este escrito no es unánime en el análisis historiográfico acerca del origen del Estado. Un planteamiento diferente puede ser consultado en: Fioravanti, Maurizio, Constitución,

Editorial Trotta, Madrid, 1991 (Capítulo 2). Fioravanti afirma que existe una idea según la cual la Edad Media habría sido un paréntesis, «[...] la edad del eclipse de la constitución, comprendida entre lo antiguo y lo moderno, la edad en la que la conciencia colectiva de la necesidad de una ley fundamental se disuelve». El texto mencionado estudia varios aspectos de la sociedad política medieval con base en la literatura que se produjo a partir del Siglo XII: la concepción existente sobre el ámbito de libertad de cada persona según el estamento al que pertenecía, las responsabilidades a cargo del príncipe, los límites a su poder y la posibilidad de que se convirtiese en tirano, el derecho de resistencia por parte de la población, etc. Aunque comparto que al soberano le correspondía velar por la integridad y por los intereses de la población (más como población que como conjunto de individuos) y que su poder no era absoluto, creo que la posición de Fioravanti podría dar lugar a que se pensase que el soberano medieval tenía una mayor responsabilidad respecto de los derechos que la que creo que tenía. Sobre este particular, debe observarse que la función del soberano en la Edad Media era proteger a la sociedad mas no representar la voluntad pública, como sucede en el Estado moderno. ${ }^{4}$ Fioravanti, Maurizio, Constitución, p. 48. 
Así, e independientemente del alcance que haya tenido en tanto que estatuto de creación o de consolidación de la comunidad política y de reconocimiento del lugar de los diferentes estamentos públicos, la Carta Magna definió -tal vez por primera vez- el ámbito de ejercicio del derecho a la propiedad privada y dio origen a una cierta concepción de la libertad muy particular en los países de habla inglesa según la cual ésta va de la mano de la propiedad.

En mi concepto, es éste el momento histórico en el que surge una «definición negativa» de los derechos en tanto que barreras contra la acción del Estado. Esta concepción «negativa» de los derechos habrá de encontrar su plena realización varios siglos más adelante, en el Estado liberal burgués.

\section{Nosotros, los liberales}

Voy aquí a dar un salto de unos cinco o seis siglos para mostrar el cambio radical que vive el Estado a partir del Siglo XVII; me refiero al Estado liberal de derecho que surge luego de las dos grandes revoluciones que tuvieron lugar en esa época, la Americana y la Francesa.

El Estado liberal surge como resultado de la habilidad que tuvieron los liberales de apoderarse del más grande tesoro de los revolucionarios -y, en especial, de los revolucionarios franceses-: la soberanía popular, y de ponerla al servicio de su causa: el establecimiento de un sistema normativo basado sobre el principio de la igual distribución de derechos y garantías entre los individuos.

Este escenario coincide con aquél con el que habían soñado de tiempo atrás los contractualistas británicos seguidores del iusnaturalismo, entre los cuales tal vez el más representativo sea John Locke: un sistema político encargado de garantizar a todas las personas el ejercicio de los derechos naturales, por medio de un sistema jurídico emanado del libre acuerdo de voluntades entre iguales aplicable de manera general y abstracta, en el cual cada quien se comprometía a depositar en un tercero representante de la voluntad general, el derecho al uso de la fuerza ${ }^{5}$.

\footnotetext{
${ }^{5}$ Ver Locke, John, Ensayo sobre el gobiemo civil, Alianza Editorial, Madrid, p. 29 y 112. En efecto, al inicio del Segundo ensayo sobre el gobierno civil, en su Capítulo II (Del estado de naturaleza), Locke afirma: «Será necesario que tengamos en cuenta cuál es el estado en el que se hallan naturalmente los hombres para entender bien en qué consiste el poder político y para remontarnos a su verdadera fuente, a mencionar: un estado de libertad completa para organizar sus acciones y para disponer de sus propiedades y de sus personas según crean, sin necesidad de pedir permiso y sin depender del arbitrio de otra persona, dentro de los límites de la ley natural». En el Capítulo VIII del mismo texto (Del comienzo de las sociedades políticas), retoma esta idea en los siguientes términos: «Siendo, según se ha afirmado ya, los hombres libres, iguales e independientes por naturaleza, ninguno de ellos puede ser arrebatado de ese estado y dominado por la autoridad política de otros sin que intervenga su propia autorización. Esta se otorga a través de un pacto hecho con otros hombres de unirse y contribuir en una comunidad designada a proporcionarles una vida grata, firme y pacífica de unos con otros, en el disfrute tranquilo de sus propias posesiones y una protección mayor contra cualquiera que no conforme esta comunidad»
} 
En este contexto, la idea según la cual la función primordial del Estado consiste en actuar como garante de los derechos civiles o «negativos», es una consecuencia lógica. Los revolucionarios -en especial, los franceses- creían que la revolución era permanente, es decir, que el Estado se fundaba a sí mismo en cada instante según la voluntad del poder soberano, el pueblo. Los liberales, por el contrario, creían que la revolución se limitaba a la toma de la soberanía por parte del pueblo, quien tendría, en ese momento, la facultad de adoptar, por medio de la deliberación autónoma, las normas generales y abstractas que habrían de regir su comportamiento. Su oposición a la concepción radical de los revolucionarios obedecía a que, en estas condiciones, el establecimiento de un sistema jurídico estable era imposible.

La soberanía popular, por lo tanto, queda limitada en este modelo de Estado a la organización de la administración pública y a la expedición de las normas sobre los derechos civiles. Las normas sobre la administración pública tienen un valor meramente instrumental: consagran los procedimientos a los que ella debe ceñirse para el desarrollo de sus funciones. Por el contrario, las normas sobre los derechos tienen valor por sí mismas dado que contienen los derechos y las garantías que permiten a los individuos la búsqueda de su felicidad. Cabe entonces preguntarse si, en este contexto, la garantía de los derechos es, en realidad, un elemento esencial del Estado. Creo que no. Las funciones del Estado liberal clásico consisten en (i) expedir las normas generales y abstractas, necesarias y suficientes, para la protección de los derechos civiles; (ii) abstenerse de interferir en el goce de los mismos; y (iii) sancionar a quienes los vulneran. De esta forma, en el modelo jurídico liberal, se considera que una vez expedidas las normas, la función del ordenamiento jurídico y de su administración por parte de los jueces queda limitada a la asignación de penas y compensaciones.

En el Estado medieval, la garantía de los derechos no era en realidad un problema. Es cierto que había una forma de administración de justicia y que el Soberano era el llamado a solucionar las diferencias entre los particulares, pero la existencia de los derechos de los particulares era más el resultado de negociaciones y acuerdos -entre los cuales el más significativo es la Carta Magna- que un elemento de la definición misma del Estado. El Estado liberal, por su parte, supone la efectividad de los derechos: para los liberales, un sistema jurídico fundamentado sobre normas generales y abstractas aplicadas por funcionarios judiciales imparciales bastaba para las garantías necesarias para que los individuos pudiesen hacer uso de sus derechos.

El conflictivo año de 1848 y los movimientos sociales que lo sucedieron en gran parte de los países de Europa, evidencian que el Estado liberal no había logrado solucionar los problemas que lo habían originado. 


\section{El Estado social de derecho: en busca de la igualdad básica}

La segunda mitad del Siglo XIX es testigo del desespero de miles de personas a causa de las condiciones de abandono, explotación y miseria a las que se ven sometidas. En particular, el conflictivo año de 1848 simboliza el momento a partir del cual un sector enorme de la sociedad manifiesta que no disfruta de los derechos que le habían sido prometidos, la propiedad y la libertad; que carece de la posibilidad de obtenerlos; y que, en esa medida, no goza de los valores bajo los cuales se había fundado el Estado liberal. El clamor de ese sector de la sociedad que comienza a exigir que se le garanticen condiciones mínimas de vida, habría de generar un nuevo cambio en las bases sobre las que se funda el Estado.

Las razones por las cuales el Estado liberal fracasa, quedan por fuera de nuestro análisis. Baste afirmar que a partir de ese momento se inicia el proceso de construcción de lo que más adelante recibirá el nombre de Estado social de derecho.

Este proceso, por supuesto, no es lineal. De hecho, el artículo 21 de la Declaración de los derechos del hombre y del ciudadano de 1793 señalaba que «[1]a beneficencia pública es una deuda sagrada. La sociedad debe asegurar la subsistencia de los ciudadanos desgraciados, proporcionándoles trabajo o garantizando los medios de existencia a los que están en incapacidad de trabajar».

Sin embargo, no es sino hasta mediados del Siglo XIX cuando la preocupación por las condiciones reales de vida de los seres humanos se convierte en un problema políticamente relevante, que da origen a medidas concretas para su solución ${ }^{6}$. De ahí en adelante, el Estado experimentará una serie de cambios que habrán de modificar su razón misma de ser.

Escapa de las posibilidades de este escrito determinar en qué momento se da este cambio cualitativo, es decir, en qué momento las políticas asistenciales que habían nacido a partir de la segunda mitad del Siglo XIX -políticas que implicaban un incremento cuantitativo de los recursos gestionados por el sector público- se transforman en los mecanismos propios de un modelo de Estado cuya función primordial consiste en promover la efectividad real de los derechos de los seres humanos consagrados en los ordenamientos jurídicos.

\footnotetext{
${ }^{6}$ Cfr. García Pelayo, Manuel, Las transformaciones del Estado contemporáneo, Editorial Alianza Universal, Madrid, 1995, p. 18. García Pelayo describe la situación en los siguientes términos: «En efecto, desde el último tercio del Siglo XIX se desarrolló en los países más adelantados una «política social» cuyo objetivo inminente era remediar las pésimas condiciones vitales de los estratos más desamparados y menesterosos de la población. Se trataba así de una política sectorial, no tanto destinada a transformar la estructura social cuanto a remediar algunos de sus peores efectos y que no precedía, sino que seguía a los acontecimientos»
} 
Me limitaré a hacer mención de algunos de los elementos que en mayor medida y desde diferentes ángulos permiten apreciar la dimensión de esta transformación:

a) Desde la óptica macroeconómica, tal vez el avance más importante sea el modelo keynesiano que rompe por completo la idea de un Estado imparcial, ajeno a las fuerzas del mercado, y lo convierte, al mismo tiempo, en jugador y en árbitro de la política económica.

b) La red de servicios públicos de cobertura universal y las políticas asistenciales que se adelantaron en Europa luego de la terminación de la Segunda Guerra Mundial, incrementaron notoriamente la influencia del Estado en las condiciones de vida de las personas de esos países.

c) La Ley Fundamental de Bonn de 1949 introduce en el derecho constitucional el concepto mismo de Estado social de derecho. En efecto, su artículo 20 (que versa sobre los fundamentos del orden estatal), comienza con la siguiente frase: «La República Federal de Alemania es un Estado federal, democrático y social».

d) El nacimiento de acciones y mecanismos jurídicos para la protección de los derechos fundamentales garantiza un vínculo directo entre la Constitución y los individuos. De esta manera, la posibilidad de contar con mecanismos que permitan la garantía de los derechos de rango constitucional (al menos, los fundamentales) se convierte en un derecho en sí mismo.

e) El incremento de los mecanismos de participación política ha permitido que los ciudadanos hagan parte de la definición de las actuaciones del Estado por medio de canales que, lejos de cuestionar las instituciones (como pensaban los revolucionarios franceses), las fortalecen. Así, el individuo no sólo es receptor sino también creador de derechos -sin que para ello tenga que recurrir al ámbito constituyente.

f) El crecimiento de los espacios en los que el Estado regula el comportamiento de los particulares con la finalidad de garantizar la función social de la propiedad. En la sección siguiente de esta ponencia veremos si ello es justificable, hasta qué punto y en qué condiciones.

Concluyo: fue necesario que hubiera un proceso histórico de unos siete u ocho siglos para que la garantía efectiva de los derechos se convirtiera en el núcleo de la definición del Estado. Es en este escenario en el que la pregunta por el costo de los derechos cobra sentido. En efecto, la pregunta por el costo de los derechos permite conocer no sólo las consecuencias fiscales del tipo de Estado que hemos adoptado sino también la estructura económica misma de los derechos de los que gozamos y su distribución entre los diferentes sectores de la sociedad. Las dos secciones siguientes abordan esta cuestión. 


\section{Las libertades económicas y la acción del Estado}

La sección anterior permite obtener las siguientes tres conclusiones: i) en la concepción liberal clásica, se tuvo la idea de que el goce de los derechos se encontraba garantizado en la medida en que hubiera normas generales y abstractas que los consagraran; en este contexto se consideraba que los mecanismos necesarios para su efectividad (básicamente litigiosos y policiales) tenían aplicación sólo cuando las normas eran vulneradas ${ }^{7}$; ii) esos derechos eran de carácter «negativo», es decir, se trataba de derechos cuyo goce era posible en tanto que ámbitos excluidos de la intervención del Estado, hecha la salvedad de su actuación residual en los casos en que se presentaban violaciones a las normas vigentes; iii) sólo a partir del Siglo XIX y, de manera definitiva desde la tercera década del Siglo XX, el Estado adquiere la obligación -jurídicamente exigiblede garantizar condiciones de bienestar para la sociedad y sus individuos por medio de la satisfacción de necesidades individuales concretas; de esta manera surge un nuevo tipo de derechos, los derechos «positivos o prestacionales» que, a diferencia de los derechos civiles y políticos, implicaban gasto -al menos gasto destinado a satisfacer intereses de carácter individual- para el Estado y para los contribuyentes.

La cuestión a determinar es si en la actualidad la división entre «derechos negativos» $\mathrm{y}$ «derechos positivos» es presupuestalmente sostenible a la luz de la evidencia de la que disponemos. Para tal efecto, retomaremos algunos de los elementos observados en el aparte anterior y los analizaremos desde una óptica económica.

En el Estado liberal, la garantía de los derechos, en especial los económicos, consiste en que: i) por regla general el Estado se abstenga de intervenir en el goce de los derechos de los individuos; ii) que lo haga tan solo cuando ello sea necesario, es decir (a) para obtener por medio de los impuestos los recursos que se requieren para su funcionamiento o (b) para sancionar a los infractores de las leyes; y iii) que lo haga de acuerdo con normas generales y abstractas, aplicables en igualdad de condiciones a todas las personas.

\footnotetext{
${ }^{7}$ De hecho, la visión que se tuvo del derecho en plena era liberal burguesa, es la de una ciencia negativa en sí misma. En efecto, el fragmento que se cita, tomado de un autor contemporáneo que ha estudiado el tema, lo refleja: «Un editorial aparecido en el órgano autorizado de la comunidad industrial, el Engineering News and Railroad Joumal, del 3 de febrero de 1893 anota lo siguiente: «El atractivo de la ingeniería se ha visto notoriamente incrementado por las oportunidades que ésta ofrece, desde la estricta línea del trabajo profesional hacia otras y (generalmente) más lucrativas ocupaciones en las que el entrenamiento y la práctica de la ingeniería constituyen una excelente preparación. Esto resulta del hecho de que la ingeniería es una profesión práctica y creativa, a diferencia de las antiguas profesiones, medicina, derecho, y teología, que, si mucho, son sólo negativamente creativas, pues previenen de la destrucción que de otra manera resultaría de los vicios y debilidades de los hombres».
} 
Se pensaba que eran éstos los requisitos que habrían de garantizar una asignación autónoma e impersonal de los recursos de acuerdo, exclusivamente, con las fuerzas generadas por las decisiones y las expectativas del conjunto de los actores económicos, es decir, por parte del mercado perfecto.

En este contexto, la libertad, y, más concretamente, la libertad de mercado, juega un papel fundamental. La libertad de mercado es la posibilidad que tiene cada individuo de entrar al mercado o salir del mismo, bien sea como comprador o como vendedor, cuando así se lo indique su voluntad. Ahora, esta definición, sencilla en apariencia, contiene una dificultad: el goce efectivo de la libertad de mercado, en tales términos, implica el derecho a la igualdad: para que exista libertad efectiva de mercado es necesario que cada quien puede entrar o salir del mismo en igualdad de condiciones ${ }^{8}$.

Llegamos así al punto de partida: en un mercado perfecto existe una relación directa entre la razón que lleva a una persona a adoptar una decisión económicamente relevante y el resultado que consigue. Ello explica que en este modelo la igualdad se encuentre atada a la libertad: un individuo es libre sólo si sus decisiones racionalmente adoptadas y ejecutadas le permiten obtener el resultado deseado sin que haya factores externos -en particular, terceras personas- que puedan interferir entre la decisión que éste adopta y ejecuta, y el resultado que obtiene.

Las revoluciones del proletariado que tuvieron lugar a partir de 1848 hicieron evidente que el modelo liberal burgués no había conseguido los propósitos y los fines sobre los que se encontraba fundado. En la situación de miseria y de marginación en las que se encontraba un sector enorme de la sociedad, el derecho la libertad, es decir, el derecho de cada individuo de elegir de manera racional sus fines y los medios para alcanzarlos, más que una utopía era una burla.

En términos económicos, se afirma que este tipo de situaciones indeseables se deben a que el mercado no funciona en condiciones de perfección. Cuando el mercado presenta fallas no hay una asignación igualitaria de oportunidades; esto conduce a que no todas las personas tengan la posibilidad de obtener el resultado que desean al adoptar las decisiones racionales que, en un mercado perfecto, serían conducentes para el efecto.

\footnotetext{
${ }^{8}$ Cabe insistir en que la igualdad no consiste, en el modelo de economía perfecta, en que todos dispongan de los mismos bienes y oportunidades, sino en que todos gozan de la posibilidad de adoptar las decisiones que quieran y de obtener los resultados racionalmente esperados independientemente de su situación económica. De hecho, los economistas sostienen que en un mercado perfecto, el nivel óptimo de eficiencia se puede alcanzar independientemente de cual sea la asignación de los recursos. Por ello, la teoría muestra que en un mercado perfecto, una sola reasignación bastaría para garantizar, al mismo tiempo, la equidad y la eficiencia.
} 
Los programas de atención a las personas marginadas que se pusieron en marcha en la segunda mitad del Siglo XIX, según vimos en la sección anterior, es un primer ejemplo de una política pública cuya finalidad es hacer frente a la fallas del mercado. Más adelante, la introducción del modelo keynesiano con el propósito de conjurar la crisis del 29, conduce a que el ámbito de intervención del Estado no se limite a «los casos marginales» sino que incluya el manejo mismo de las variables macroeconómicas para garantizar la sostenibilidad del sistema. De esta manera, el principio de neutralidad del Estado frente a la economía, que había sido el pilar fundamental de los liberales, queda por completo superado.

Ahora, es claro que la intervención del Estado en la economía es en sí misma restrictiva de la propiedad privada en la medida en que limita la facultad que cada quien tiene de disponer de la misma según su voluntad ${ }^{9}$. Sin embargo, y esto es lo paradójico, en los sistemas económicos actuales, los límites impuestos por el Estado a la propiedad privada y a la libre iniciativa por medio de la intervención estatal, son una condición necesaria para el goce de estos derechos.

De hecho, los economistas saben desde hace mucho tiempo que corregir las fallas del mercado y garantizar su funcionamiento en condiciones competitivas hasta donde sea posible, involucra una gran cantidad de recursos; el volumen de literatura disponible sobre esta materia y la cantidad de premios Nobel que han recibido quienes se dedican a su estudio, es indicativo de su importancia ${ }^{10}$.

\footnotetext{
${ }^{9}$ Ver Hayek, Friedrich, The Road to Serfdom, Routledge, London, 1993. p. 53. Por ejemplo, Hayek sostenía que la planeación económica, cuando se extendía más allá de los aspectos sobre los cuales existía el libre acuerdo de los individuos, terminaba por ser arbitraria en sí misma. En su opinión, «la creencia según la cual si el poder procede de un procedimiento democrático, es un poder democrático», es completamente falsa. «Si la democracia decide sobre una materia que necesariamente envuelve el uso de un poder que no se encuentra en las reglas prees tablecidas, éste necesariamente será un poder arbitrario» (No obstante las palabras de Hayek, las democracias contemporáneas hoy reconocen que (i) las facultades de intervención estatal van más allá del mero pacto entre actores privados; (ii) que ello implica una afectación de la facultad de elegir en la medida en que las decisiones son, en muchos caso, preadoptadas por las instituciones estatales; y (iii) que ello hace parte de la estructura orgánica de los sistemas democráticos en tanto que mecanismos para garantizar su sostenibilidad institucional. ${ }^{10}$ Ver Stiglitz, Joseph, El papel económico del Estado. Instituto de Estudios Fiscales, Madrid, 1993. Entre ellos, Stiglitz sostiene que «Las características específicas del Gobierno -asociación universal y poder de coerción- le proporcionan ciertas ventajas en la corrección del las deficiencias del mercado». Estas ventajas son, según Stiglitz, (i) el poder impositivo, (ii) el poder de proscripción (es decir, el poder de prohibir ciertas actividades), (iii) el poder sancionatorio y (iv) la capacidad de reducir costos por medio del fortalecimiento de organizaciones productivas, el control sobre el uso de los bienes públicos y otras formas de regulación). También la literatura colombiana registra este fenómeno. Al respecto, puede consultarse el aparte «El Estado como protector del mercado« en: Palacios Mejía, Hugo, La economía en el derecho constitucional colombiano, Editorial Derecho Vigente, Bogotá.
} 
Lo que no se ha puesto suficientemente de presente es que estas acciones que emprende el Estado protegen, en últimas, un derecho en concreto: el derecho de propiedad. Esta omisión ha sido la causa de que la concepción según la cual los «derechos negativos» son aquellos cuya garantía consiste en la prohibición de que el Estado intervenga en su goce sea una verdad petrificada, que se repite a lo largo del tiempo, así no existan ya las condiciones que la originaron.

De esta manera, creo que la polémica acerca de si el Estado debe o no intervenir en la economía, carece de lugar. El problema, más bien, consiste en determinar si el Estado debe intervenir para crear o fortalecer la libre competencia entre los particulares o si lo debe hacer para establecer que la asignación de los recursos (o de algunos de estos) se realice por medio de sistemas diferentes al de la concurrencia de la oferta y la demanda ${ }^{11}$.

No obstante, e independientemente de cuál sea la opción que se escoja en cada caso, hay al menos dos condiciones que se cumplen en todos los casos: i) la intervención del Estado implica siempre la utilización de recursos públicos; y ii) la intervención del Estado siempre protege algún interés -el cual debe ser legítimo desde la óptica pública aunque ello no siempre suceda ${ }^{12}$.

${ }^{11}$ Cfr. Allen, David, "Copetition Policy: Policing the Single Market", en: Wallace, Helen y Wallace, William. Policy-Making in the European Union, Oxford University Press, 1997.p. 160.

El fragmento que se cita a continuación, el cual pertenece a un artículo sobre la política europea en materia de competencia económica, muestra el punto: «La política para implementar la competencia tiene tanto un rol negativo como uno positivo en la evolución de la Comunidad Económica Europea. De un lado, se relaciona con la promoción del mercado por medio de la aplicación de sanciones contra aquellos que buscarían abusar de o restringir estas libertades. Podría argumentarse aquí que no hay necesidad de una política como tal, sino simplemente la exigencia de que las leyes sobre competencia perfecta, archivadas en los tratados, deban ser utilizadas, usando para ello los procedimientos allí establecidos. De otro lado, la política de competencia puede ser vista en un rol positiva, a partir de la creación del libre mercado y

-dirán algunos- de las estructuras y de los comportamientos industriales que la caracterizan. En la medida en que el segundo rol requiere de la adopción de decisiones, existe la necesidad de una política que las guíe».

${ }^{12}$ Holmes, Stepehn, y Sunstein, Cass, The Cost of Rights, Why Liberty Depends on Taxes, W.W. Norton \& Company, New York, 1999, p. 224. Stephen Holmes y Cass Sunstein ofrecen, sobre este particular, el siguiente argumento, que vale la pena rescatar: «Lejos de ser cruelmente economicista, un estudio de las condiciones fiscales de la protección de los derechos, es fundamentalmente política. Reparar en los costos nos obliga a tomar una más amplia y no una más restringida óptica del bienestar público. Ello nos previene de asir los problemas en forma secuencial, en la medida en que van surgiendo, y nos obliga a proponer soluciones globales a una amplia gama de los problemas sociales. Además, deja desnuda la necesidad de la inversión pública, hecha y evaluada en forma colectiva. Más que reflejar una admiración ciega a los productos del mercado, el estudio del costo de los derechos tiene significado en la promoción de políticas públicas producto del razonamiento. Es también un tema comunitario o colectivista, no obstante tener profundas raíces en la tradición política liberal» 
La sección siguiente se encarga de analizar la dimensión de esta polémica en el campo de los hechos.

\section{Análisis de casos para una aproximación a la dimensión del estudio del costo de los derechos}

Esta sección muestra algunos casos que evidencian el alcance del análisis del costo de los derechos. En efecto, este campo de investigación (i) permite cuestionar la solidez de las bases sobre las que se encuentra fundamentada nuestra cultura jurídica; (ii) proporciona información valiosa acerca de la asignación real de recursos y de oportunidades entre los diferentes sectores de la sociedad; y (iii) ayuda a tener claridad respecto de la legitimidad y la efectividad de las políticas que se adoptan para la protección de ciertos valores jurídicos.

Aclaro que no se trata de un listado exhaustivo ni de un análisis sistemático sino de una mera recolección de ejemplos que refuerzan la tesis sostenida a lo largo de esta ponencia según la cual la clasificación de los derechos entre negativos y positivos es presupuestalmente insostenible:

1. La libertad económica y la propiedad privada no son «derechos negativos» ni gratuitos. Por el contrario, su garantía requiere de la intervención permanente del Estado, lo cual implica la utilización de gran cantidad de recursos públicos.

No me refiero únicamente a los mecanismos que la tradición reconoce como protectores de la propiedad, es decir, la policía o el sistema de justicia, que son, sin lugar a dudas, instituciones cuya existencia es inseparable del concepto mismo de «derecho» en tanto que conjunto de mecanismos dispuestos por el Estado para garantizar ese derecho ${ }^{13}$.

Contemplo, en especial, los instrumentos de los que se valen los estados contemporáneos para garantizar la efectividad de la propiedad privada y del libre mercado. El sistema de registro de bienes raíces y acciones, marcas y patentes, y de propiedad industrial, por ejemplo, así con la exigencia de que se concedan garantías por parte de los productores o vendedores de ciertos bienes y servicios a sus compradores, proporcionan una idea acerca de la cantidad de mecanismos jurídicos disponibles -y quizá indispensables- para la protección del derecho a la propiedad privada.

\footnotetext{
${ }^{13}$ Si la seguridad o la justicia son en realidad servicios indivisibles que protegen de manera igualitaria a todos los ciudadanos, tal como pensaban los defensores del Estado liberal, es un tema que no será abordado en esta oportunidad pero que guarda una relación directa con este análisis.
} 
La garantía de la libertad de mercado, por su parte, incluye medidas que van desde las reglas relativas a la provisión de información suficiente por parte del productor o vendedor acerca de ciertos bienes o servicios (ingredientes de los productos alimenticios, por ejemplo) hasta la legislación anti-monopolios, el control a los carteles y a la repartición de mercado. La búsqueda de garantías para la libertad de mercado se extiende incluso al ámbito internacional, en donde los países negocian entre sí que se limiten prácticas restrictivas tales como la concesión de subsidios a los productores locales, o la imposición de barreras a las importaciones como aranceles elevados, cuotas, o medidas reglamentarias discriminatorias.

Puede así constatarse que la propiedad privada y la libertad de mercado dependen de una intrincada red de normas, instituciones y procesos que son resultado de situaciones adversas que el mercado es incapaz de resolver y que dan lugar a la intervención del Estado ${ }^{14}$.

Adicionalmente, es claro que todas estas normas, instituciones y procesos requieren de alguien que se encargue de su funcionamiento y de su aplicación, y que su funcionamiento y aplicación genera unos costos enormes ${ }^{15}$.

2. La pregunta por el costo de los derechos muestra de quién son en realidad los derechos que protegemos. El mercado laboral proporciona un ejemplo interesante sobre el que existe una polémica aguda. En las últimas dos décadas se han puesto en marcha una serie de políticas cuyo propósito consiste en flexibilizar las normas relativas al mercado laboral. Se trata de políticas orientadas a permitir que el costo del trabajo sea determinado por el mercado y no por medio de regulación estatal, que se reduzcan los requisitos de despido de los empleados y que se limite el derecho a la huelga.

\footnotetext{
${ }^{14}$ No significa lo anterior que el Estado tenga la capacidad de resolver cada uno de los fallos del mercado y que su intervención sea eficiente en todos los campos. En efecto, los estudios sobre los fallos del Estado muestran los límites de la intervención estatal y los costos que ésta genera. Un resumen de la literatura disponible sobre este tema, puede ser consultado en: Stiglitz, Joseph, La economía del sector público, Antoni Bosch Editor, Barcelona, 1997. (En especial los capítulos 6-"La elección pública"-, 7 -"Producción pública y burocracia"-y 8 -"Externalidades"-, analizan este problema).

${ }^{15}$ Sólo para proporcionar una idea de este costo, es interesante observar que el presupuesto de la Nación vigente para el año 2002 (Ley 714 de 2001), contempla una partida presupuestal de más 28.112 millones de pesos para la Superintendencia de Servicios Públicos Domiciliarios; de caso 182.900 millones de pesos para la Superintendencia de Notariado y Registro; de 63.632 millones de pesos para la Superintendencia Bancaria; y de 47.715 millones de pesos para la Superintendencia de Sociedades. Es decir, estas cuatro instituciones, todas ellas ejemplo de entidades encargadas de garantizar el funcionamiento del mercado o de simularlo, cuestan más de 320.000 millones de pesos. Dada esta evidencia, iserá cierto que la libertad de mercado no nos cuesta nada?
} 
Los defensores de esta posición sostienen que en muchas oportunidades la protección del mercado laboral favorece tan solo a quienes gozan efectivamente de empleo (quienes obtienen así salarios más altos, mayor seguridad laboral y disponen de un buen portafolio de motivos para interrumpir las actividades y realizar protestas) y perjudica a los desempleados debido a que, en estas condiciones, los empleadores se verán obligados a hacer previsiones más detenidas al momento de incorporar nuevos trabajadores, lo cual desincentiva su contratación.

Sin embargo, no hay consenso respecto de esta posición. Sus críticos señalan que las medidas de flexibilización del mercado laboral han generado una mayor concentración de la riqueza debido a que el trabajo, en tanto que factor de producción, tiene en la actualidad un costo más bajo (un costo que, a la vez, es el ingreso del empleado), lo cual conduce a un incremento de las utilidades por parte de los empleadores y a un empobrecimiento relativo y constante de los empleados ${ }^{16}$.

No profundizaremos en el estudio de este debate. Nos limitamos a poner de presente que el análisis del costo de los derechos ayuda a estudiar el impacto de este tipo de políticas y establecer cuáles son los beneficios (y los beneficiarios) de cada una de las medidas adoptadas para su implementación. Este tipo de análisis conduce a se pueda establecer a quién pertenecen los derechos que protegemos ${ }^{17}$.

\footnotetext{
${ }^{16}$ Ver Navarro, Vicenc, Neoliberalismo y Estado de Bienestar, Ariel Sociedad Económica, Barcelona, 1997. En este texto, su autor toma datos estadísticos de las últimas cuatro décadas y las utiliza para comparar la evolución social tanto antes como después de que se pusieran en marchas las políticas de flexibilización del mercado laboral a comienzos de los años 80's en Europa y los Estados Unidos. ${ }^{17}$ Las sentencias proferidas por la Corte Constitucional respecto del incremento salarial de los servidores públicos proporcionan un caso interesante respecto del tipo de intereses y de derechos que se protegen según la óptica con la que se aborden los problemas jurídicos. En la Sentencia C-1433 de 2000 (M.P. Antonio Barrera Carbonell) la Corte declaró la inexequibilidad por omisión del presupuesto vigente para ese año en la medida en que no había contemplado un incremento salarial para todos los servidores de acuerdo con la inflación. Esa corporación consideró que todos los servidores tenían el derecho constitucional a que se les incrementara el salario según el aumento en el costo de vida. Esta posición fue modificada por la Sentencia C-1064 de 2001 (M.P. Manuel José Cepeda Espinosa y Jaime Córdoba Triviño). En este segundo fallo se afirmó que si bien existe el derecho constitucional al incremento salarial, éste no es absoluto. Este argumento permitió que la Corte constatara (i) que el incremento en el costo de vida, si bien matemáticamente es igual para todos los servidores con independencia de su nivel salarial, en términos reales afecta en mayor medida a los de ingresos más bajos; (ii) que el país atravesaba por una difícil situación económica; y (iii) que el incremento diferencial de los salarios de los servidores públicos era necesario para evitar el desbordamiento del déficit fiscal, el despido de algunos de ellos y la reducción de la inversión social. Este razonamiento condujo a la Corte a privilegiar las medidas a favor del control del déficit y de una mayor disponibilidad de recursos para inversión en lugar de favorecer el derecho de los servidores de mediano y alto nivel de ingreso a contar con un incremento salarial equivalente a la inflación.
} 
3. El tema relativo al costo de la protección de los derechos es diferente al de los derechos que efectivamente decidimos proteger. La protección efectiva de un derecho es consecuencia de (i) su consagración en el ordenamiento jurídico (y, en particular, en el texto constitucional) y (ii) de la capacidad del Estado de garantizar aquello que se encuentra definido en las normas.

En un primer momento, se trata de una cuestión política: piénsese, por ejemplo, en las luchas y reivindicaciones que tuvieron lugar a lo largo de los Siglos XIX y XX para que el trabajo adquiriera la condición de derecho y, más adelante, de derecho fundamental. El alcance que tenga en un momento dado un derecho, es decir, hasta dónde sea protegible, hace parte de esta primera fase (aunque tiene implicaciones más o menos inmediatas en el segundo momento) ${ }^{18}$.

En un segunda fase, el problema es de efectividad: iqué tanta aplicabilidad tienen las prescripciones normativas, es decir, qué tan protegido se encuentra en el campo de los hechos un derecho que ha sido consagrado en el ordenamiento jurídico?

En este contexto, la pregunta por el costo de los derechos cobra importancia. En efecto, el grado de efectividad de un derecho se encuentra íntimamente ligado a: i) su alcance según su descripción normativa, lo cual se define en el momento de su consagración en el ordenamiento y de su posterior desarrollo jurisdiccional; ii) la cantidad de recursos que se destinan para su protección; y iii) la adecuada gestión de dichos recursos.

De esta manera, el estudio económico de un derecho permite conocer: i) su efectividad; ii) su importancia presupuestal; y iii) la eficiencia en el manejo de los recursos que se destinan para garantizar su goce.

Se trata de problemas diferentes aunque íntimamente relacionados. El primero muestra qué tanta aplicación tiene una norma constitucional cualquiera en la que se consagre un derecho; el segundo versa sobre una cuestión numérica: a cuánto asciende el gasto destinado a garantizar el goce de ese derecho; el tercero permite evaluar los resultados de las políticas que se han puesto en marcha para garantizar tal derecho ${ }^{19}$.

\footnotetext{
${ }^{18}$ Por cierto, debe tenerse en cuenta que el nivel de protección de los derechos no es siempre creciente. De nuevo, el derecho al trabajo nos ofrece un buen ejemplo: a partir de la terminación de la Segunda Guerra, este derecho se vio fortalecido por una serie de prescripciones normativas orientadas a garantizar la estabilidad laboral, el salario mínimo, la seguridad social, las políticas de protección industrial, etc. Algunas de estas garantías se han visto limitadas en muchos países, según lo vimos arriba.

${ }^{19}$ Un análisis sobre la dimensión y la eficiencia del gasto público en Colombia, puede encontrarse en Clavijo, Sergio, Política fiscal y Estado en Colombia. Banco de la República y Universidad de Los Andes, Bogotá, 1998. En este texto, su autor estudia el impacto y el costo que han tenido diferentes políticas públicas respecto de la promoción de ciertos valores y derechos (salud, educación, seguridad ciudadana); igualmente se incorporan índices que permiten medir la efectividad del gasto público en los sectores en los que se invierte.
} 
Este método de análisis permite también hacer comparaciones respecto del costo que tienen los diferentes derechos consagrados en la Constitución. Sería interesante, por ejemplo, hacer una comparación entre la cantidad de recursos públicos que utilizamos para la protección del derechos de propiedad ${ }^{20}$ (en nuestra Constitución, un derecho económico) y la cantidad que destinamos para la libertad de investigación ${ }^{21}$ (consagrado como derecho fundamental en nuestra Carta).

El análisis del costo de los derechos ayuda a hacer claridad en el uso que se hace de los recursos públicos, es decir, permite evaluar si en efecto hay una correspondencia entre la naturaleza normativa de un derecho y el esfuerzo presupuestal que éste genera ${ }^{22}$.

${ }^{20}$ Hemos visto ya la enmarañada red de instituciones por medio de las cuales se protege la propiedad privada y las libertades económicas. La investigación acerca del costo que tiene la protección estos derechos supone establecer entre otras, la cantidad de recursos que destinamos a esas instituciones, el tiempo que instituciones como la Policía, los Jueces e incluso, el Congreso de la República utilizan para su protección, y el costo que ello genera, etc.

${ }^{21}$ Respecto de esta afirmación habría una crítica posible según la cual es diferente garantizar una libertad (la libertad de investigación, por ejemplo) y destinar dineros públicos para brindar una garantía o un derecho contemplada en la Constitución (el derecho a la educación). Stephen Holmes y Cass Sunstein ofrecen evidencia interesante que muestra hasta qué punto esta diferencia es sostenible en el campo de los hechos. Comentan que en el caso Roe vs. Wade, la Corte Suprema de los Estados Unidos protegió el derecho de una mujer a que se le practicara un aborto. Más adelante, en el caso Maher vs. Roe, la misma Corte sentenció que no había obligación alguna por parte del Estado de sufragar una intervención quirúrgica de esta naturaleza a una mujer indigente y que la decisión del Estado de financiar tan solo la atención de las mujeres embarazadas, no implicaba que las que quisieran abortar estuvieran en una situación de desventaja. Holmes y Sunstein muestran con base en este caso que la línea que diferencia una libertad de una prestación es difusa. En efecto, la negativa del Estado a financiar la solicitud de aborto de esta mujer, condujo a que su libertad no fuera más que teórica, es decir que, dada situación económica, no tenía en lo absoluto la libertad que reclamaba (Cfr. Holmes, S. y Sunstein, C. The Cost of Rights. Why Liberty Depends on Taxes. W.W. Norton \& Company; New York, 1999).

${ }^{22}$ La tradición jurídica anglosajona es sensible a la relación que estos países se percibe entre el esfuerzo fiscal a que conlleva la protección de un derecho o un valor y su importancia real. Así, por ejemplo, en el caso Brown vs. Board of Education (1954) la Corte Suprema de los Estados Unidos señaló lo siguiente: «Hoy, la educación es quizá la más importante función del Estado y de los gobiernos locales. Las leyes de asistencia obligatoria a la escuela y el enorme gasto que se hace en educación, demuestran nuestro reconocimiento de la importancia de la educación en nuestra sociedad democrática». Sin querer hacer una polémica sobre el punto, creo que es sugestivo preguntar si no existe acaso una relación entre aquellos propósitos que consideramos importantes y el esfuerzo que hacemos para alcanzarlos; si acaso el esfuerzo fiscal que hace una sociedad para proteger un derecho no proporciona elementos de juicio respecto de la importancia que realmente se le concede. 
4. No obstante el punto anterior, la forma como es consagrado un derecho en el texto constitucional colombiano define los mecanismos de los que se dispone para su protección; así, el artículo 85 de la Carta Política enuncia los derechos «de aplicación inmediata». No es ésta una consagración vacía. La condición de derecho «inmediatamente aplicable» implica que los individuos disponen de herramientas expedita y confiable para exigir al Estado su cumplimiento.

Aprovecho acá la oportunidad para saldar una deuda pendiente y contestar una pregunta que me fuera formulada cuando tuve la oportunidad de hacer la presentación de esta ponencia en la Universidad Icesi. Es cierto que en Colombia hay miles de personas que carecen incluso de lo mínimo para soportar la vida. En tales condiciones hay, de facto, una vulneración de la Constitución: en la situación de abandono en que se encuentran estas personas, valores tales como la igualdad, la dignidad o la libertad (todos tres, derechos de inmediata aplicación) tienen muy poco o quizá ningún significado. La cuestión es, entonces, si tiene sentido consagrar derechos «de aplicación inmediata» en la Constitución cuando no se cuenta con los recursos o con la disposición política de dar cumplimiento efectivo a lo que ella prescribe. No obstante el peso de la evidencia en contrario, creo que la decisión del Constituyente de haber dado a ciertos derechos la condición de inmediatamente aplicables, ha permitido que haya soluciones concretas a las necesidades de algunos individuos. La Sentencia T1330 de 2001 (M.P. Manuel José Cepeda Espinosa) proporciona un ejemplo valioso. En ella se revisó la acción de tutela interpuesta por una tercera persona a favor de un anciano que se encontraba en una situación humillante de abandono, para que se le protegieran los derechos y garantías básicas ${ }^{23}$.

\footnotetext{
${ }^{23}$ Los términos en los que fue interpuesta la acción de tutela que se analiza, permiten ver las condiciones de marginalidad y exclusión en las que se encontraba el anciano beneficiario de la misma. El accionante sostuvo que interponía la acción de tutela «[...] en venefisio de un tersero que se encuentra en el momento abandonado y privado de las capasidades físicas para haserlo pues se encuentra postrado en una silla de ruedas y carece de memoria y moviento en las manos. Para inponer este recurso, pues considero la nesesida de haserlo ya que se estan violando o bulnerando los derechos a los cuales la nasion y el estado le otorga y esta en la obligacion de hacerlos respetar [...] el señor se encuentra inbalido ya no reconose y no tien a nadie a su lado que lo acompañe y vea de el se encuentra abandonado a su suerte desde hase varios dias, al suscrito lo cuidava una señora que se fue de su lado y lo dejo solo. Como es un inbalido que no puede reclamar, el estado le esta dando la espalda y lo que hasen los organismos es reducirlo. Tenemos el caso de las empresas publicas que le cortaron los servicios negandole el derecho a una vivienda dicna, en el ospital no lo atienden negandole el derecho a la salud y en un sentro de reposo no lo resiven negandole el derecho a un anciano y ademas munisbalido de esta forma redusen a una persona a vivir en la miseria el abandono y el desamparo y yo pregunto donde esta el derecho a la igualda a la vivienda, a la salud y el los derechos de un minusbalido» (Sentencia T-1330 de 2001).
} 
El juez de instancia consideró que, a pesar de la dramática situación en la que se encontraba el anciano, la acción interpuesta no era procedente porque había sido interpuesta contra la Secretaría de Salud del municipio, quien era la encargada de la prestación del servicio, y no contra la Secretaría de Planeación, responsable de adelantar las encuestas del Sisbén ${ }^{24}$ para que se le pudiese incorporar en el régimen subsidiado de salud.

La Corte Constitucional en esa oportunidad: i) reiteró que «Los derechos a la salud (CP art. 49), a la seguridad social integral (CP art. 48), y a la protección y asistencia a la tercera edad (CP art. 46), en principio programáticos, pueden verse actualizados y generar un derecho público subjetivo de inmediata aplicación (CP arts. 13 y 85), si la persona interesada demuestra fehacientemente su condición de debilidad manifiesta y la imposibilidad material de su familia para darle asistencia, en particular cuando la completa ausencia de apoyo lo priva de su derecho al mínimo vital $»^{25}$; ii) señaló que la efectividad de los derechos consagrados en la Carta depende de la actuación concurrente y coordinada de los órganos del Estado; iii) recordó que, de acuerdo con las normas constitucionales sobre el régimen territorial, las entidades territoriales son destinatarias de transferencias por parte de la Nación, las cuales tienen como destino el cumplimiento de su cometido institucional ${ }^{26}$; iv) afirmó que la obligación del Estado respecto de la protección de los derechos fundamentales de las personas se extende hasta el punto en que se garantizara el pleno goce de los mismos, según su situación.

Con base en estas consideraciones, la Corte ordenó no sólo que se incluyera al beneficiario de la tutela en el régimen subsidiado de salud sino que se le proporcionaran los cuidados y la atención en un lugar apropiado, de acuerdo con su condición de persona de la tercera edad.

Reconozco, sin embargo, que justificar la utilidad de haber consagrado en la Carta Política un tipo de derechos «de aplicación inmediata» a partir de un ejemplo (hay otros, lo cual no desvirtúa el punto que se estudia), es insatisfactorio: si los derechos son «de aplicación inmediata», ipor qué hay entonces un número tan significativo de personas que no disponen de las condiciones mínimas para llevar

\footnotetext{
${ }^{24}$ El Sisbén es un sistema de medición que permite identificar las condiciones económicas de los miembros de la sociedad con el propósito de vincularlos a la red de seguridad social, especial aunque no únicamente, en materia de salud.

${ }^{25}$ Corte Constitucional. Sala Segunda de Revisión. Sentencia T-426 del 24 de junio de 1992, M.P. Eduardo Cifuentes Muñoz.

${ }^{26}$ En efecto, la Corte puso de presente en esa oportunidad que «el numeral $2^{\circ}$ del artículo 21 de la Ley 60 [que en ese entonces regulaba lo relativo al uso de los recursos transferidos a los municipios por parte de la Nación en virtud del artículo 357 de la Constitución vigente para la fecha] indican que una de las funciones de los municipios en materia de salud consiste en financiar «programas de la tercera edad y de las personas con deficiencias o alteraciones físicas y mentales, en cualquiera de sus modalidades de atención».
} 
una vida digna? 'por qué no se dispone de un mecanismo administrativo expedito que garantice la satisfacción de tales derechos? ipor qué en muchas oportunidades es necesario recurrir a las acciones judiciales (en especial, a la tutela) para -no siempre ${ }^{27}$ - obtener aquello que debería estar garantizado per $s e ?^{28}$

Si bien no es tan alentador como se quisiera, la existencia de mecanismos judiciales por medio de los cuales se pueda obtener una prestación, en tanto que derecho fundamental, por parte del Estado o de otros obligados a tal efecto abre, por lo menos, la posibilidad de que los individuos obtengan la protección que la Constitución o la jurisprudencia constitucional definen, lo cual, en todo caso, ayuda a que se consolide una cultura de la protección de los derechos.

5. En un Estado social de derecho, no siempre es al Estado a quien corresponde proteger los derechos fundamentales y sobre quien recae toda la carga

${ }^{27}$ Cfr. Abramovich, Victor y Curtis, Christian, Los derechos sociales como derechos exigibles.

Editorial Trotta, Madrid, 2002. Como muestra el caso que se analiza, la interposición de una acción judicial para obtener una prestación por parte del Estado, definida en el texto constitucional como «derecho fundamental», no garantiza que el juez conceda la protección solicitada. Es sintomático que una de las razones que hubiera dado el juez para negar la tutela, es que ésta no se hubiera interpuesto contra la entidad deudora de la prestación que, en concreto, se requería en esa oportunidad (la reclasificación del anciano en el sistema de registro del Sisbén) sino contra la entidad encargada de velar por la prestación del servicio (a pesar de ser ambas, instituciones de la Alcaldía y de que cada una de ellas se encarga de una etapa diferente aunque necesaria para la prestación que se solicitaba). Sobre este particular, Victor Abramovich y Christian Curtis sostienen que, en términos generales, los sistemas judiciales de los país es occidentales continúan atados a los mecanismos pertinentes para la protección de los derechos civiles y políticos. Los argumentos esgrimidos por el juez muestran que no sólo en los sistemas judiciales sino incluso en la mentalidad de los jueces se registra la dificultad de adoptar concepciones jurídicas y categorías mentales adecuadas para garantizar la efectividad de los llamados derechos prestaciones.

${ }^{28}$ La tradición jurídica kelseniana sostiene que la condición sine qua non de existencia de un derecho es la existencia de un mecanismo judicial que asegure su exigibilidad. Así, por ejemplo, Victor Abramovich y Christian Curtis sostienen lo siguiente: «Aunque un Estado cumpla habitualmente con la satisfacción de determinadas necesidades o intereses tutelados por un derecho social (por ejemplo, si desarrolla un amplio programa de provisión de alimentos a la población amenazada por el hambre), ningún observador podría afirmar que los beneficiados por la conducta estatal gozan de un derecho [...] como derecho subjetivo hasta tanto verificar si la población se encuentra en condiciones de demandar judicialmente la prestación del Estado ante un eventual incumplimiento» (Cfr. Abramovich, V y Curtis, C. Ibídem. Pág. 37). Si bien comparto la afirmación según la cual la existencia de mecanismos judiciales es necesaria para garantizar la exigibilidad de un derecho, me parece preocupante que esta posición pueda dar lugar a que la efectividad de un derecho esté condicionada a la interposición de una acción judicial. En efecto, pienso que hay una relación inversa de proporcionalidad entre la efectividad real de un derecho y la cantidad de acciones que se interponen para exigir su cumplimiento por parte del Estado o de quien sea el obligado de su prestación. 
económica que ello implica. Algunos ejemplos permiten ponerlo de presente:

a. La legislación laboral colombiana prevé que el aporte al Sistema General de Pensiones de las cotizaciones de las pensiones de los empleados estará a cargo de ellos y del empleador. Este último, además, es el responsable de efectuar el pago correspondiente ${ }^{29}$.

b. Las reglas vigentes en Colombia sobre la prestación de los servicios públicos domiciliarios garantizan a los usuarios el derecho a presentar quejas y reclamos a las empresas prestadoras de tales servicios, incluso cuando se trata de empresas privadas. Para tal efecto, el Régimen de Servicios Públicos Domiciliarios señala que todas las empresas prestadoras de servicios públicos domiciliarios tendrán una oficina encargada de dicha función y que corresponde a la misma empresa prestadora del servicio conocer, en primera instancia, de los recursos que interpongan los usuarios respecto de las quejas o reclamos que sean formulados ${ }^{30}$, lo cual supone un costo de funcionamiento ajeno a su actividad productiva.

c. Por vía de la jurisprudencia, encontramos también casos que resultan ilustrativos. Por ejemplo, en la Sentencia T-604 de 1992 (M.P. Eduardo Cifuentes Muñoz), la Corte Constitucional resolvió una tutela interpuesta por un accionante de un barrio periférico de una ciudad que consideraba vulnerado su derecho y el de la comunidad a la que representaba, al servicio público de transporte. La empresa prestadora del servicio argumentó que no recorría el último tramo de la ruta asignada debido a que no era rentable. La Corte encontró (i) que el derecho al transporte público presenta una íntima conexidad con «los derechos al trabajo (CP art. 25) a la enseñanza (CP art. 27), a la libre circulación (CP art. 24) y, en general, al libre desarrollo de la personalidad (CP art. 16)»; (ii) que ello los hace objeto de «la protección constitucional del artículo 86 de la Constitución [es decir, de la acción de tutela] cuando su desconocimiento se traduce en una inmediata vulneración o amenaza de los mencionados derechos»; (iii) que la ruta en su totalidad era rentable, lo que garantizaba el derecho de la empresa prestadora del servicio a obtener utilidades por su actividad; (iv) que las empresas prestadoras de servicios públicos cumplen una función social respecto del goce de los derechos fundamentales de los individuos; $(v)$ que en virtud de esa función social, es legítimo imponer ciertas cargas a estas empresas que si bien limitan el ámbito de su libertad económica, resultan necesarias para proteger los derechos fundamentales de los individuos que requieren de su prestación ${ }^{31}$.

\footnotetext{
${ }^{29}$ Ver artículo 22 de la Ley 100 de 1993.

${ }^{30}$ Ver artículos 152 y 154 de la Ley 142 de 1994.

${ }^{31}$ Ver Sentencia T-604 de 1992, M.P. Eduardo Cifuentes Muñoz.
} 
6. Muchas veces el costo de la protección de los derechos es indirecto y su protección se traslada de unas personas a otras. Un caso representativo, al que ya habíamos hecho referencia, es el de las normas relativas a la protección del consumidor. Cuando una norma exige ciertas características o requisitos para la comercialización de un bien o servicio, eleva sus costos, los cual es asumido por el comprador ${ }^{32}$. En esas oportunidades, el ordenamiento jurídico exige que los compradores de tales bienes o servicios paguen por la protección de sus propios derechos.

7. Hay oportunidades en las que la protección de los derechos no es neutral sino que se utiliza para defender o incluso para esconder intereses particulares. El mercado de banano en los países de la Unión Europea muestra cómo la defensa de ciertos derechos supone la protección de intereses particulares. A principios de los 90 la Unión Europea se vio obligada a establecer reglas uniformes respecto de la comercialización del banano que para ese entonces no hacía parte del mercado común europeo. Hasta ese momento, la oferta de banano para los países de la entonces Comunidad Económica Europea (CEE) provenía de cuatro fuentes diferentes: la producción local (por parte de España, Francia y Grecia), la de las antiguas colonias africanas, la de las antiguas colonias del Caribe (que contaban ambas con un tratamiento preferencial por parte de los países en los que esta producción era comercializada) y la de los países de América Central y del Sur. Es interesante observar que para 1992, la tonelada de banano Centro y Suramericano (que cuenta con alto nivel de calidad) tenía un costo de 412 ecus; la de las ex colonias caribeñas, de 599; la de las ex colonias africanas, de 619; y la de banano doméstico (de baja calidad) ascendía a 72033. Así pues, la decisión adoptada por los gobiernos de algunos países (España, Francia y Grecia) de proteger el derecho al trabajo de sus productores locales o los beneficios comerciales concedidos a sus ex colonias (Reino Unido y Francia) por medio de la imposición de barreras comerciales (aplicables de manera diversa por los diferentes países según la procedencia del banano), condujo a que (i) los consumidores de los países que habían impuesto tales barreras tuvieran que pagar un alto precio para adquirir banano de mala calidad; (ii) que los países que contaban con ventajas competitivas respecto de este producto (Colombia, por ejemplo), vieran frustradas sus legítimas aspiraciones de tener libre acceso al mercado de los países protectores; y (iii) que los consumidores de los países en los que se había permitido el funciona-

\footnotetext{
${ }^{32}$ En este país, por ejemplo, es obligatorio que los automóviles tengan cinturón de seguridad y que los tiquetes de las líneas aéreas comerciales estén acompañados de un seguro de vida para el pasajero.

${ }^{33}$ Ver Stevens, Chistopher, "EU Policy for the Banana Market: The External Impact of Internal Policies", en Wallace, Helen y Wallace, William, Policy-Making in the European Union, Oxford University Press, 1997.
} 
miento del mercado (Alemania y Benelux) en condiciones competitivas, pudieran adquirir banano económico y de alta calidad.

Las medidas contra el dumping social o el dumping ambiental, por su parte, proporcionan evidencia sobre situaciones en las que no se muestran los intereses que se protegen sino que se esconden. Se dice que existe «dumping social»o «dumping ambiental» cuando un país que no cuenta con garantías laborales o con mecanismos adecuados de protección ambiental, exporta productos a precios sensiblemente competitivos. De esta manera, el dumping social o el ambiental se utilizan para justificar la imposición de barreras comerciales a tales productos. Este comportamiento se apoya en dos argumentos: «1) argumento ético: obligación del norte de defender los derechos laborales [y las condiciones ambientales] de la población de los países del sur; 2) argumento económico: carácter desleal de estas exportaciones y perjuicio económico que genera en los países del norte» ${ }^{34}$.

Cuando un país impone barreras de ingreso de un producto a su territorio con el argumento de que tal producto es resultado del dumping social o ambiental, ibusca proteger los derechos sociales o ambientales de la gente de los países de origen del producto o en realidad se protegen los intereses del país que impone barreras? Más aún, si es cierto que su preocupación es, por ejemplo, los derechos laborales de quienes se ven obligados por las circunstancias a trabajar en condiciones desfavorables, ino quedarán incluso peor si pierden su empleo como consecuencia de las restricciones económicas impuestas?

8. Creo que no podría terminar un análisis sobre el costo de los derechos sin hacer mención de los beneficios a que conlleva su protección. ¿Qué tanto se beneficia la sociedad de contar con un sistema eficiente de provisión del servicio de salud? ¿Cuál es la relación que hay entre una política educativa que garantice a todos el acceso a una educación básica de buena calidad y la tasa de desarrollo económico? ¿En cuánto desciende la tasa criminalidad o la de violencia intrafamiliar con la construcción de parques o bibliotecas públicas? iEn qué medida se beneficia la sociedad de programas de capacitación de empleados, de fomento industrial, de apoyo a las exportaciones? ¿Qué tanto mejora nuestra condición humana el hecho de que exista un programa eficiente de asistencia a los niños o ancianos indigentes para que tengan opciones diferentes de vida a las que encuentran en las calles o en las alcantarillas de las ciudades?

\footnotetext{
${ }^{34}$ Oyarzún De Laiglesia, Javier, "El dumping social: el estado de la cuestión", Boletín Económico del ICE N² 2553; 22 a 28 de septiembre de 1997. p. 26. El autor sostiene que el dumping social esconde una posición defensiva de los estados que lo utilizan para imponer barreras comerciales.
} 